\title{
Leadership in interprofessional collaboration in health care
}

\author{
Anne Katrine Folkman' \\ Bodil Tveit ${ }^{2}$ \\ Sidsel Sverdrup ${ }^{2}$ \\ 'Centre of Diaconia and Professional \\ Practice, VID Specialized University, \\ Oslo, Norway; ${ }^{2}$ Faculty of Health \\ Studies, VID Specialized University, \\ Oslo, Norway
}

This article was published in the following Dove Medical Press journal: Journal of Multidisciplinary Healthcare

\begin{abstract}
Purpose: There is a need to develop more knowledge on how frontline managers in health care services facilitate the development of new roles and ways of working in interprofessional collaborative efforts and the challenges they face in daily practice. The article is based on a study that examines the modes of governance adopted by frontline managers in Norway, with a special focus on leadership in collaborations between the Norwegian profession of social educator and other professions.
\end{abstract}

Materials and methods: A qualitative research design was chosen with interviews of eleven frontline managers from district psychiatric centers, municipal health care services and nursing homes.

Results: The results show that frontline managers largely exercise leadership in terms of selfgovernance and co-governance and, to a lesser degree, hierarchical governance. Self-governance and co-governance can facilitate substantial maneuverability in terms of professional practice and strengthen both discipline-related and user-oriented approaches in the collaboration. However, one consequence of self-governance and co-governance may be that some occupational groups and professional interests subjugate others, as illustrated by social educators in this study. This may be in conflict with frontline managers' abilities to quality assure the services as well as their responsibility for role development in their staff.

Conclusion: The results show that frontline managers experience challenges when they try to integrate different professions in order to establish new professional roles and competence. Frontline managers need to support individual and collective efforts in order to reach the overall goals for the services. They must be able to facilitate change and support creativity in a working community that consists of different professions. Moreover, the social educator's role and competence need clarifications in services that traditionally have been dominated by other clinical and health care professions.

Keywords: health care personnel, social care personnel, interprofessional collaboration, managerial anchoring, front line managers competencies, roles

\section{Introduction}

Internationally, the development of new strategies and ways of working in the health care occupations has, over the course of a few years, led to a greater degree of interprofessional collaboration. Based on a shortage of health care personnel, a growing need for services among users, new requirements and expectations in relation to service user participation and citizenship, new ways of collaboration between professions are called for. ${ }^{1-4}$ As early as 2010, the Framework for Action on Interprofessional Education
Correspondence: Anne Katrine Folkman Centre of Diaconia and Professional Practice, VID Specialized University, Vågsgate 40, Oslo, Norway $\mathrm{Tel}+4790655 \mathrm{II} 8$

Email anne.katrine.folkman@vid.no 
and Collaborative Practice WHO described interprofessional collaboration as an innovative way of meeting the complex service needs of the future. Adequate and effective leadership is essential to addressing such needs. ${ }^{5-9}$

In Norway, interprofessional collaboration between health and social care personnel has been an important health political priority. ${ }^{10}$ A number of different means can be used to reach these health political overall goals. The focus in this article is on leadership of interprofessional collaboration in three different health care services, with particular attention on social educators. Social educators work especially in service provision to people with cognitive impairment. They are trained to conduct environmental work and habilitation and rehabilitation with people with physical, mental and/ or social disabilities. Social educators are authorized health care providers, and they are trained to handle drugs. ${ }^{11,12}$ The social educator's competence is, however, not a key municipal service such as nursing. ${ }^{13}$

Service areas that social educators have not traditionally worked in include mental health, dementia care and municipal health care services. ${ }^{13}$ When social educators move into these health care service areas, new collaboration partnerships are created and knowledge overlaps occur with other practitioners such as nurses. This overlap might expose challenges in interprofessional collaboration. ${ }^{14}$ Studies show that social educators and nurses are involved in ongoing negotiations on the division of labor in interdisciplinary settings. ${ }^{15,16}$ These studies point to a need for clearer leadership and managerial anchoring, and systematic reflection on tasks that can be taken care of by different professions.

International research refers to several factors that can complicate leadership in interprofessional collaboration. Leaders may lack understanding of the specific professional roles and responsibilities of the different occupational groups. ${ }^{8}$ Role blurring can become a major issue in interprofessional collaboration. Core challenges are how the workforce perceives new roles and tasks: are they willing to work in different settings, assume new tasks and responsibilities and contribute to a new mix of skills? ${ }^{16}$ Other challenges may include underlying professional cultures and values, power coalitions and territorial behavior between the professions. ${ }^{18,19}$ All these factors can lead to role dominance with limited communication and coordination of the collaborative efforts between the professions. $^{3}$

Challenges associated with the systematic organization of work in relation to which professions should perform which tasks can be problematic. There is also a need for more systematic training of staff and clearer lines of responsibility.
Several international studies show that consistent and strong leadership, as well as clear support from leaders, could contribute to the development of new roles in the collaboration and to making personnel feel secure in these. It will also foster a better understanding of communality in a professional setting and develop new relationships and ways of working. ${ }^{8,9}$ If it is unclear who is the leader of the team, or there are conflicts related to leadership, conflicts may arise in attempts to encourage participation in decision making. The consequence may be reduced interaction, influence and information sharing. ${ }^{21}$ There is a need for more knowledge on how leaders coordinate and organize interprofessional collaboration in the health care service area and on the challenges they face. 5,7

This study examines how frontline managers in Norway facilitate interprofessional collaboration in three health care services, with a special focus on managing social educators and nurses in their daily practice. The question posed in the article is as follows: What are frontline managers' experiences with leadership in interprofessional collaboration? This issue is elucidated through three research questions: Which modes of governance do frontline managers employ in leadership in interprofessional collaboration? What opportunities and challenges do frontline managers encounter in leadership in interprofessional collaboration? What opportunities for interprofessional collaboration do frontline managers envisage between a "new" profession such as social educator and other professions?

\section{Leadership and professions as theoretical concepts}

Abbott ${ }^{22}$ highlights how competition, knowledge and power affect task distribution between the professions. This provides important input into possible sources of friction that occur between professional practitioners. Abbott shows how this dynamic affects both interaction and professional practice and how it can lead to both a breakdown in the collaboration and stagnation. ${ }^{22}$ His theory is, therefore, relevant in this article. However, Abbott says little about what implications his theory ought to have for leadership in interprofessional fields of work. Kooiman ${ }^{23}$ is concerned with how leadership cultures in interprofessional fields of work are created in a context that is closely linked to the professional practitioners' knowledge and knowledge production. He examines how the interactions between managers and their staff and between the different professional practitioners are characterized by disparities in knowledge and relationships of dependence between those involved. Kooiman's interaction perspective 
is suitable for understanding both the process on the micro level as well as ongoing collaboration between managers and their employees. In addition, his theory is suitable for understanding health policy on the macro level. Kooiman ${ }^{23}$ has developed three theoretically different modes of governance. The first, self-governance, refers to the individual's capacity to govern him/herself, and practitioners' opportunities to develop their own identity and autonomy. According to Kooiman, ${ }^{23}$ the professional's individual capacity for interpretations and definitions of the role of professions has been expanded. This shift leads to greater self-governance in professions at an individual level.

The second mode of governance, co-governance, entails shared responsibility and interaction, where the parties involved formally organize themselves. An important aspect of co-governance is making service users part of the shared responsibility. The goal is to develop a more adequate service provision. Increasing specialization and differentiation of services, and the interaction needed to accommodate these, necessitate this form of leadership. "Learning by doing" enables the various participants to create a common conceptualization of activity. ${ }^{23}$

The third mode of governance, hierarchical governance, is characterized by a top-down approach and targeted activity. This requires goals to be set, tools to be selected, strategies to be designed and various activities to be coordinated and controlled. Hierarchical governance comes into being when power coalitions and relations change, and is more in line with a structural level. ${ }^{23}$

The terms "self-governance", "co-governance" and "hierarchical governance" are, therefore, suitable tools for analyzing how frontline managers perform leadership in interprofessional collaboration.

\section{Materials and methods}

In order to elucidate the issue and research questions, a qualitative research design was chosen. Qualitative studies aim to develop an understanding of the social phenomena being studied and are suitable for studying relatively unexplored themes. ${ }^{24}$ The qualitative research interview explores individuals' experiences. ${ }^{25}$ By interviewing frontline managers in the health care service area, we were able to explore own perspectives of their daily work. The purpose of the interviews was to explore different modes of governance based on frontline managers' experiences with challenges and opportunities in interprofessional collaboration. The study thus contributes to the development of management theory in the health care service area.
The data material consists of interviews with eleven frontline managers from district psychiatric centers, municipal health care services and services for the elderly in nursing homes. The collection of the interview material was terminated at the saturation point. The interviews were conducted by the first author, a sociologist, at the manager's workplace. Each interview lasted $\sim 75$ minutes.

The project has been approved by the Norwegian Center for Research Data (NSD ref. no. 41287). Data production took place in the autumn of 2016. Written informed consent was obtained from all participants, and research ethics requirements for anonymization were met. All interviews were conducted in Norwegian and the responses were translated to English with the assistance of a professional editor.

\section{Participants}

A strategic approach known as the snowball method was used to recruit the sample. The informants were selected due to their position and responsibility for coordination of interprofessional collaboration. Frontline managers from the three service areas were invited for the individual interviews. In order to meet the inclusion criteria, the frontline managers had to have been employed in the service area for at least 1 year and have daily contact with their staff. Three of the informants were men with a nursing background. Eight were women: two qualified social educators, one ergonomist and five nurses. The informants had work experience from various health and social care service areas, such as environmental therapy, habilitation and rehabilitation, nursing and care work, and administration. The groups of professions and occupations they managed consisted of health workers, care workers, auxiliary nurses, nurses, social educators, child care workers, ergonomists, educators, social workers, art therapists, doctors, psychologists and psychiatrists.

\section{Data collection}

The three service areas represented in the study offer health care services to different target groups. All three service areas are examples of "new areas of work" for social educators.

A semi-structured interview guide ${ }^{25}$ was used in the individual interviews with frontline managers. The guide focused on managerial anchoring, competence, training and collaborative practices. All the themes were represented in the theory. The questions concerned recruitment, division of labor and responsibilities, special needs for competence and skills development. The frontline managers were specifically asked about social educators' competence and training needs. Other questions were about collaborative practices related 
to the facilitation of interdisciplinary and interprofessional exchanges and activity, tensions or conflicts in the staff groups and positioning. Audio recordings were made of the interviews and the first author transcribed these.

\section{Analysis}

Analysis of the material is inspired by thematic analysis by Vaismoradi et $\mathrm{al}^{26}$ and Thagaard. ${ }^{27}$ The analysis was conducted as a process moving backward and forward between the entire data set, the coded extracts of data and the data that were produced. Codes and themes were based on research literature. Both Abbott's and Kooiman's theories offer possible explanations of the complexity in interprofessional collaboration. Abbott's understanding of competition, power and knowledge was useful for analyzing the relationship between professions and between professions and frontline managers. Kooiman's theory was useful for analyzing management in this setting.

Data analysis took place in three nonlinear steps. The first step consisted of a thorough reading and coding based on the research question, with a view to identifying patterns of concurrence and divergence both longitudinally and transversely in the data set. In the next step, the data set was systematically reviewed and coded. The codes formed the basis for extracting relevant text, which was then condensed. In the third step, the codes were sorted and developed into subthemes that were categorized and organized into overarching themes. The analysis process took place as a collaboration among the three authors with the aim of strengthening the validity of findings. ${ }^{25}$ It should be noted that interpretations might be influenced by the first and third authors' understanding, which is related to their sociological background. Competition, knowledge and power are concepts that sociologists often find to be of particular relevance to professions in the health and welfare field.

Overall, the analysis provided the basis for highlighting three themes that are relevant to discussion of the issue and the research questions on frontline managers' experiences with leadership in interprofessional collaboration.

\section{Results}

The three themes analyzed in the material refer to modes of governance in the sense of qualitative dimensions of areas of leadership in interprofessional collaboration and are termed modes of governance, opportunities and challenges in leadership in interprofessional collaboration and social educators' opportunities in interprofessional collaboration. These themes are used to elucidate the main problem and the research questions that arise.

\section{Theme I: modes of governance}

This theme describes frontline managers' different modes of governance in interprofessional collaboration in the services via two subthemes: "self-governance and co-governance" and "patient-centered care".

\section{Self-governance and co-governance}

Several of the managers indicated that there is an increasing requirement for professional qualifications. This may be one reason for preference being given to candidates with qualifications from professional studies and preferably with postgraduate education that is relevant to the service area. The managers found that this gives the individual service provider independence and confidence in their role, which is vital across service levels and interprofessional collaborative efforts. One manager explains this as follows:

If we're too rigid and say that the specialist health services should do this and do that, we'll never be able to make it work. We need to be flexible and see the bigger picture in order to achieve anything. [Frontline manager, district psychiatric center]

Several of the managers expressed that interdisciplinary recruitment can help improve services. They described opportunities for the different professional groups to work together on developing a better and more holistic service provision. Meanwhile, several managers also believed it is up to each professional group and employee to promote their skills and contributions in the collaborative effort. Some managers acknowledged that they sometimes find it challenging that staff with strong preferences in terms of their work and areas of interest can subjugate others. This can prevent the points of view and ideas of other professional groups coming to the fore. The following quote illustrates this:

Nevertheless, we still manage to use the strengths and weaknesses of the professions to some extent, but I think it would be beneficial to make them even clearer. [Frontline manager, district psychiatric center]

Nevertheless, the material shows a trend for managers generally avoiding involvement in how the different professional groups contribute with their disciplinary knowledge.

\section{Patient-centred care}

Another trend identified in the material is the managers' descriptions of how treatment collaboration is changing. According to the managers, the focus on professional 
expertise was previously more one dimensional, while there is now much more focus on service users' functioning, resources and coping skills. The managers note how this shift in focus has created new roles and other ways of working together. A stated goal is that service users should play a more central role in the collaborative effort, which may lead to the various professional practitioners serving more as "guides" or "assistants". One manager gives an example of how a perspective based on service users' coping skills and resources can change perceptions of roles and professional contributions:

They (the recipients) tell us about their experiences and how we should work. They want us as a guide or assistant, they're not bothered about what our professions are. [Frontline manager, municipal health care services]

Several managers said that patient-centered care as a common professional basis for collaboration primarily requires service providers to engage with those in need of help and the challenges they describe. One issue that was raised is that providing a service largely depends on whether service providers are able to establish good relations with service users, with professional affiliation being of secondary importance. Another change that several managers considered to be essential for collaboration was in the design of the services and evaluation of professional practice. It should be measured against service users' experiences and assessments to a much greater extent. This has led to a significant change in how competence is viewed, based on entering compromises with service users and their families, who are regarded as the users' representatives. Observations by managers suggest that this change makes disciplinerelated assessments more taxing. One manager describes the change as follows:

We need to be more informative and involve service users` families in the decision-making process. This challenges us and our service, which I believe is very positive. They keep an eye on us. [Manager, municipal health care services]

\section{Theme 2: opportunities and challenges in leadership in interprofessional collaboration}

This theme refers to the opportunities and challenges that frontline managers experience in leadership in interprofessional collaboration in the service areas they manage. These are described in two subthemes: "roles and status" and "power of definition of the disciplines".

\section{Roles and status}

Several managers said that restructuring and changes in responsibilities and duties might be necessary not only to better meet overarching requirements for a more comprehensive service provision, but also to quality assure the services with a view to greater access to information and broader interprofessional collaboration in accordance with health policy guidelines.

The managers stated that such guidelines had entailed reorganization. Reorganization has resulted in challenges that have been difficult to solve because it has affected the sense of ownership by some professions vis-à-vis certain target groups and services. The managers expressed that it has been particularly challenging to argue for the need for nurses to have broader professional knowledge. This particularly applied in reorganization entailed that nurses had to participate to a greater extent in responsibilities and duties in home-based services. Managers found that their ambitions to have broad competence in all services provision may conflict with nurses' wishes to retain certain professional tasks and responsibility areas. One manager gives the following example:

Especially nurses who worked with substance abuse and psychiatric patients and conversations at the office, were now expected to deal with service users with intellectual disabilities. It meant a professional struggle that was difficult to solve, especially between nurses and social educators.

[Frontline manager, municipal health care service]

The managers are concerned about the importance of retaining nurses. Several described the nurses' competence as indispensable. They gave examples of how they have also worked to give social educators and social workers greater access to information and more responsibility for services that were previously the preserve of nurses. This has led to greater professional transparency and breadth and has improved the climate for collaboration, according to some managers. However, they add that the personnel's perception that some responsibilities and duties and certain roles have a higher status than others can still be a challenge, as exemplified in the quote above. The managers find that strong professional interests can mean a lower standard of quality in certain parts of the services than in others because discipline-specific contributions do not come to the fore 
as desired. One such challenge is the collaborative efforts between social educators and nurses, as illustrated by the following quote:

It almost seems as if social educators are more concerned about being nurses than being social educators. Mastering these traditional nursing tasks well rather than being aware of how the skills of social educators and nurses differ? [Frontline manager, district psychiatric center]

\section{Power of definition of the disciplines}

According to some managers, a great deal of work is being carried out on clarifying what interprofessional collaboration should entail, both in the district psychiatric centers and in the municipal health care service. Interprofessional collaboration is also a focus area in the collaboration across these service levels. Much is still measured on the basis of individual and clinical diagnoses. Some managers also describe the medical language as imperfect and insufficient as a basis for broader interprofessional collaboration and for understanding patients. One manager expresses this as follows:

If there is a lot of focus on illness, and medicines are the singular and overarching solution, this is not necessarily in line with our experience. We need more focus on what has not been integrated in standard practice. [Frontline manager, municipal health care services]

The managers provided examples of how a diagnostic culture and clinical approaches and knowledge still enable the professions they manage, such as doctors, psychiatrists and psychologists, to have the final say in the collaboration. The managers believe that both they and staff have to make a special effort and fall into line with clinical assessments that can be counter to their own opinions and sense of autonomy. One manager describes this as follows:

I can disagree vehemently with [clinical] practitioners in situations where the professional staff I manage stand up for themselves and argue for what they think is right. It is the clinical practitioners who have the final say. [Frontline manager, district psychiatric center]

\section{Theme 3: social educators' opportunities in interprofessional collaboration}

This theme elucidates the opportunities for interprofessional collaboration that frontline managers envisage between a "new" profession such as social educators and other professions, and these are described in two subthemes: "need for health care and clinical competence" and "complex needs for competence and services".

\section{Need for health care and clinical competence}

Several managers gave examples of how, as a consequence of the growing need for clinical and health care competence in the services, clinical professions have been preferred to social care and training personnel, such as social workers and educators. The managers also said that social educators are very useful due to the dual nature of their discipline, and described how the main reason for employing social educators is their clinical and health care expertise and their authorization to work as health care personnel. They described how social educators are particularly well equipped to assess health service needs for user groups with complex clinical pictures, such as substance abusers and psychiatric patients. Social educators also have the medical competence to handle medicines in collaboration with such services. The managers' descriptions suggest that this gives social educators a competitive edge over other professions, particularly in home-based services. In such service areas, social educators work alongside nurses and other occupations and professions. One manager made the following observation:

Particularly in relation to substance abuse and psychiatry, I need to have social educators because they're familiar with the users who get these medicines and also have access to where the medicine is stored. [Frontline manager, municipal health care services]

Social educators' health care and clinical competence is also the reason for employing social educators in nursing homes. The managers experienced that nurses try to steer away from some types of work, such as nursing homes and working with dementia patients. Their observations indicate that social educators are expected to be able to undertake nursing responsibilities and duties on a par with nurses. This is illustrated by the following quote:

Nurses and social educators have the greatest responsibility in relation to medicines, dispensing doses and more advanced procedures. We have a minimum workforce at the home, so we require the social educators to be competent in the majority of such tasks. [Frontline manager, nursing home]

Some of the managers still prefer to have more nurses in the staff groups than social educators, reasoning that the 
nurses have more health care expertise than the social educators. These managers also give other examples of why nurses are preferred, such as the overarching and formal requirements for nursing coverage and the introduction of more stringent requirements for competence in advanced somatic procedures. There is also some uncertainty among the informants about social educator competence and what social educators can contribute, as illustrated by the following quote:

I'm not very familiar with the qualifications of social educators. Regarding how much instruction they get about illness and [...]. I do not know enough about that. [Frontline manager, nursing home]

Consequently, several of the managers believe that it is important to find a good balance between the number of social educators and nurses.

\section{Complex needs for competence and services}

Social educators have social work competence, which the managers describe as being particularly useful for addressing the increasing number of multiple and complex service needs. The managers gave examples of duties for which this competence is suitable. One manager made the following observation:

We have practical tasks that deal with finances, housing, state benefits, guardianship. This requires a lot of administration. It's one of the fields where social educators have skills that we could put to better use than we do today.

[Frontline manager, district psychiatric center]

Several of the managers' observations indicate that health care services have become more home based and that user participation is increasingly being emphasized. Such changes require new ways of working. This could challenge more standardized perspectives in terms of service development, measurements of effectiveness and what professional practice should entail, according to several of the managers. They also believed that the combination of broad decisions on complex service needs coupled with a clearer focus on the coping skills and resources of service users requires broad disciplinary expertise and approaches. One manager gave examples of how social educator competence and ways of working can represent important disciplinary contributions that complement more traditional nursing approaches and working methods:
Social educators' relaxed mindset is so important. 'Shadowing' the service user. It may appear that social educators work less effectively, but they don't. They wouldn't manage to do what they do if they had the same parameters as the community nurses. [Frontline manager, municipal health care services]

\section{Discussion}

\section{Self-governance and co-governance?}

The health and care service area in Norway has become more complex over time and is being adapted to the needs of individual service users to a greater extent. This has led to a growing need for independent and professionally competent practitioners. The frontline managers described how working on a holistic and flexible service provision is more important than promoting differences between the disciplines and fixed responsibilities and duties. This can be understood as a type of governance ${ }^{23}$ and a way of anchoring leadership that frontline managers use to give interaction processes direction, in accordance with health policy guidelines and a profession-neutral statutory framework. Competent independent staff groups that are conscious of their own professional qualifications and roles provide frontline managers with the latitude to delegate responsibility for service development and quality assurance of the services to employees who govern themselves. This mode of governance is an example of Kooiman's description of self-governance. ${ }^{23}$ It entails personnel largely trusting in their own professional role and taking responsibility in the collaboration. The frontline managers depend on the employees and their collaboration partners to find common solutions to service needs. Nilsen et $\mathrm{al}^{2}$ also found that Norwegian nursing frontline managers in municipal services were largely dependent on support from competent staff groups.

Based on our findings, the frontline managers support participation, reflection and collaboration processes that include a clear user focus. This adds new aspects to the collaboration, where the view on competence and expertise is changed and practical experience is valued more on a par with professional competence. Such new forms of labor division and realignment of disciplines can put a strain on the concept of profession as an organizational principle, since service users are increasingly serving as a structuring principle for the collaboration. Consequently, frontline managers wishing to quality assure the services are faced with new challenges. ${ }^{16}$ In our results, greater emphasis on patient-centered care is expressed through the shift toward roles as "guides" or 
"assistants" and the growing involvement of service users in the quality assurance of disciplines.

The results show that distributing leadership, knowledge and skills and working across professions serve as a guide for the collaboration. Thus, co-governance ${ }^{23}$ also characterizes modes of governance in our study. Several international studies $^{7}$ argue for a shift away from hierarchical, individualized and traditional leadership in order to promote interprofessional clinical pathways. Contextual "dynamic delegation" of leadership in the form of co-governance paves the way for different contributors taking a leader or follower role, depending on the pathway. One of the main concerns with this mode of governance is the need to share power and authority based on knowledge and experience as opposed to role and function.

Our findings show that both self-governance and cogovernance present challenges for frontline managers, since some occupational groups and professional interests can end up in a subordinate position. New responsibilities for managers emphasize the need for a clearer leadership role and more strategic management. ${ }^{2}$ Results indicate that frontline managers do not adequately manage to exploit the potential in profession-specific contributions by self-governance and co-governance because powerful professions enact their own rules to the exclusion of others. Based on this, it is also debatable to what extent users are able to influence the quality of professional self-governance. ${ }^{23}$ Several studies ${ }^{7}$ have pointed out that traditionally, the health and care services have provided the basis for questioning collective modes of governance based on a hierarchical structure, professional territorialism and power. This concurs with issues that emerged in our material. Interprofessional work involves using a systematic and targeted approach to exploiting the opportunity afforded by the variety of competence available, and this is a management responsibility. ${ }^{28}$ Our results underline that frontline managers could put more effort to realizing this potential.

\section{The field of tension surrounding professions}

Findings show that some roles and collaborative tasks have a status among professions than others. This can be challenging for frontline managers, particularly when the need arises to reorganize responsibilities and duties among the professions. They provided several examples of how reorganization is necessary for ensuring access to information and broad interprofessional collaboration. When responsibilities and duties are changed or implemented, a battle among the professions can occur. ${ }^{19}$ In our material, this can be seen in the leadership of collaborations between clinical professions and other personnel, and between nurses and social educators. In both cases, the frontline managers' compromises in the collaboration seem to be characterized by discipline-related interests. Other studies ${ }^{9}$ show that conflicts among professional groups can be a challenge for managers when the goal is to expand roles in the collaboration. Authorization as qualified health care professionals ${ }^{11}$ has enabled social educators to compete for positions traditionally dominated by nurses. This has led to tensions between the two professions. ${ }^{12}$ The results show how strong professional interests and conflicts between the professions can hamper frontline managers' efforts to comply with overarching guidelines for broader interprofessional collaboration. Other studies s,9,16,19 $^{3}$ also point out that such challenges can mean that discipline-specific contributions do not come to the fore to the degree leaders would prefer. According to Abbott, ${ }^{22}$ professions strengthen their position by exerting control over tasks based on the skills they possess. By refusing access to alternative and competing clinical practice as a basis for collaboration, professions can promote their own status and professionalization, ${ }^{19}$ also described as "role dominance" in the collaboration. ${ }^{3}$

Our results indicate that frontline managers do not tend to use a hierarchical mode of governance. According to Kooiman, ${ }^{23}$ leaders need legitimacy to comply with overarching policy guidelines and to regulate interaction and collaboration. Changing structures and previous power relations, and the institutionalization of other and new relations require leaders to exercise governance and control. ${ }^{6,9}$ Other studies $^{21}$ show that clear leadership is essential for breaking up territorial barriers among professions, facilitating and strengthening different roles, creating and developing new relations and fostering innovative solutions. Results show that professional competence and ability to self-governance and co-governance cannot replace such management functions. Insufficient quality assurance and control represents challenges for frontline managers in Norwegian health and care services. ${ }^{28}$ More tailored management training for the health care sector is a way to accommodate this. ${ }^{29}$

\section{The contribution of social educators}

The results show that the frontline managers have different role expectations and requirements in relation to the competence of social educators. In the home-based service area, which has traditionally been the remit of social educators, the dual competence of social educators is presented as a potential asset in the collaboration. Descriptions of social educators' focus on the coping skills and resources of service 
users and their "relaxed style of working" can be understood as an expression of professional values and approaches that challenge the focus on effectiveness and traditional nursing approaches. One challenge in municipal health and care services is that the competence can be too medicalized and specialized. This makes it difficult to safeguard the breadth that is needed to meet the challenges in the daily work. ${ }^{16}$ Common purpose, commitment and mutual respect are crucial in interprofessional collaboration. ${ }^{14}$ Leaders play an important role in this work. ${ }^{6,8,9,18-20}$ Both national and international studies ${ }^{8,16}$ illustrate that leaders may lack experience with collaboration between certain groups of professions. Greater awareness and broader competence is needed among frontline managers related to the different professions' competence, in order to strengthen the new roles and work areas of collaborative professions. Our study supports this understanding, which finds support in theory. This manifests itself most clearly as a leadership challenge in institution-based service areas that are dominated by the health care and clinical professions, such as nursing homes and district psychiatric centers. It has been particularly challenging to legitimize social work and discipline-related contributions in traditional health care sector. ${ }^{8}$ Several studies ${ }^{8,19}$ demonstrate a need for managers who can help to legitimize and integrate the roles and disciplinary contributions of social care professionals in service areas dominated by the health care and clinical professions.

Social educators' combination of perspectives and disciplinary knowledge is necessary in order to understand functional impairments and functional disabilities. ${ }^{11}$ The profession's dual competence means that practitioners can apply a variety of perspectives and recognize and meet many different needs. This point of departure gives social educators the potential to play an important role as a bridge builder between professions in collaborations in various service areas. ${ }^{13}$ However, this presupposes that the social educator's competence is recognized both by the frontline managers and by the other professionals they collaborate with. Furthermore, recent studies indicate that there is a need to clarify what social care perspectives and competence should entail, both generally and in relation to social education in particular. ${ }^{15-17}$ Our findings also support the need for further clarification of the role, function and competence of the social educator in interprofessional collaboration, particularly in relation to nurses. Frontline managers' modes of governance in interprofessional collaboration will be a key factor in this work.

\section{Conclusion}

Regarding the question of what experiences frontline managers have with leadership in interprofessional collaboration, the results show that frontline managers seem to strike a balance between different modes of governance. They largely apply self-governance and co-governance and use hierarchical governance to a lesser extent. Self-governance and cogovernance can facilitate substantial maneuverability in terms of professional practice and strengthen both discipline-related and user-oriented approaches in the collaboration.

Meanwhile, greater service user control of the services puts a strain on the concept of profession as an organizational principle. In addition, self-governance and co-governance involve a greater emphasis on the ethical competence and judgment of the individual service provider, where some occupational groups and professional interests can subjugate others. Uncertainties about the professional contribution and role of social educators can be partly interpreted in this light. The situation gives little scope for questions or exchanges of views about social educators' knowledge base, and consequently, this appears to disqualify them. The findings show that, overall, such factors may be inconsistent with frontline managers' responsibility for quality assuring the services as well as developing new ways of coordinating and organizing responsibilities and duties between staff groups. One of the main aspects of leadership in interprofessional efforts will be to exploit the opportunity afforded by the variety in competence available in a systematic and targeted way in order to create disciplinary breadth.

The results highlight that social educators' broad competence should not be understood in isolation, but should be more closely linked to the occupational role, target groups and value choices of social education. In interprofessional collaborations between social educators and nurses on complex service needs, the social educators' contribution includes new forms of expertise and collaboration, pointed out by frontline managers. Target groups with multiple service needs have traditionally fallen under the remit of social education.

The results show that frontline managers experience challenges when they try to integrate different professions in order to establish new professional roles and competence. Frontline managers need to support individual and collective efforts in order to reach the overall goals for the services. They must be able to facilitate change and support creativity in a working community that consists of different professions. Our results show that frontline managers have to make an effort in this regard. Moreover, the social educator's role and competence need clarification in services that have traditionally been dominated by other clinical and health care professions.

\section{Strengths and limitations}

The leadership challenges identified are based on the experiences of frontline managers working in multidisciplinary 
settings. Both the frontline managers and staff groups included in the study consist of various groups of occupations and professions where nurses form the majority. This concurs with trends in the distribution of responsibilities and duties between nurses and other professions in interprofessional health care service areas, where nurses are also increasingly taking up managerial roles.

Our study focuses on frontline managers' experiences. For a more complete understanding, social educators, nurses and other professions also should be addressed in future studies. This may add knowledge to understand challenges related to leadership of interprofessional collaboration.

\section{Implications for practice}

The study demonstrates a need for frontline managers who are willing to enter the field of tension in which different professions' own limits for competence are challenged, in order to promote interprofessional collaboration. Our results underline a need for more knowledge on the part of frontline managers about how to exploit professional complementarity and synergies in interprofessional collaboration and adopt new approaches to roles, responsibilities and the division of labor.

\section{Disclosure}

The authors report no conflicts of interest in this work.

\section{References}

1. Fox A, Reeves S. Interprofessional collaborative patient-centred care: a critical exploration of two related discourses. J Interprof Care. 2015;29(2):113-118.

2. Nilsen ER, Olafsen AH, Steinsvåg AG, Halvari H, Grov EK. Stuck between a rock and a hard place: the work situation for nurses as leaders in municipal health care. J Multidiscip Healthc. 2016;9:153-161.

3. Nugus P, Greenfield D, Travaglia J, Westbrook J, Braithwaite J. How and where clinicians exercise power: interprofessional relations in health care. Soc Sci Med. 2010;71(5):898-909.

4. Suter E, Arndt J, Arthur N, Parboosingh J, Taylor E, Deutschlander S. Role understanding and effective communication as core competencies for collaborative practice. J Interprof Care. 2009;23(1):41-51.

5. World Health Organization. Framework for Action on Interprofessional Education and Collaborative Practice. Geneva: World Health Organization; 2010. Available from: http://apps.who.int/iris/ bitstream/10665/70185/1/WHO_HRH_HPN_10.3_eng.pdf?ua=1. Accessed January 8, 2019.

6. Asakawa T, Kawabata H, Kisa K, Terashita T, Murakami M, Otaki J. Establishing community-based integrated care for elderly patients through interprofessional teamwork: a qualitative analysis. JMultidiscip Healthc. 2017;10:399-407.

7. Brewer ML, Flavell HL, Trede F, Smith M. A scoping review to understand "leadership" in interprofessional education and practice. $J$ Interprof Care. 2016;30(4):408-415.

8. Cameron A, Lart R, Bostock L, Coomber C. Factors that promote and hinder joint and integrated working between health and social care services: a review of research literature. Health Soc Care Community. 2014;22(3):225-233.
9. Harris MF, Advocat J, Crabtree BF, et al. Interprofessional teamwork innovations for primary health care practices and practitioners: evidence from a comparison of reform in three countries. J Multidiscip Healthc. 2016;9:35-46.

10. Ministry of Health and Care Services [webpage on the Internet]. Morgendagens omsorg (Future care). In. Meld. St. 29 (2012-2013). Oslo: Departementenes servicesenter; 2013:140. Available from: https://www. regjeringen.no/contentassets/34c8183cc5cd43e2bd341e34e326dbd8/ no/pdfs/stm201220130029000dddpdfs.pdf. Accessed January 15, 2019.

11. Ministry of Education and Research [webpage on the Internet]. Rammeplan for vernepleie [National curriculum regulations for social education]. Oslo: Ministry of Education and Research; 2005:12. Available from: https:/www.regjeringen.no/globalassets/upload/kilde/ $\mathrm{kd} / \mathrm{pla} / 2006 / 0002 / \mathrm{ddd} / \mathrm{pdfv} / 269377$-rammeplan_for_vernepleierutdanning_05.pdf. Accessed January 15, 2019.

12. Messel J. I velferdsstatens frontlinje: barnevernspedagogers, sosionomers og vernepleieres historie [At the Welfare State's Front Line: The History of Child Care Workers, Social Workers and Social Educators]. Oslo: Universitetsforlaget; 2013. Norwegian.

13. Ministry of Education and Research [webpage on the Internet]. Utdanning for velferd- Samspill i praksis (Education for welfare: interaction in practice). In. meld. St. 13 (2011-2012). Oslo: Departementenes servicesenter; 2012:143. Available from: https://www.regjeringen.no/contentassets/ac91ff2dedee43e1be825fb097d9aa22/no/pdfs/ stm201120120013000dddpdfs.pdf. Accessed January 15, 2019.

14. Rämgård $M$, Blomqvist $K$, Petersson P. Developing health and social care planning in collaboration. J Interprof Care. 2015;29(4):354-358.

15. Folkman AK, Sverdrup S, Tveit B. Tverrprofesjonalitet eller innordning? En casestudie av vernepleieres forhandlinger om posisjon i distriktpsykiatriske sentre [Interprofessionality or falling into line? A case study of social educators' negotiations on position in district psychiatric centres]. Fontene Forskning. 2017;10(1):56-69. Norwegian.

16. Ludvigsen K, Danielsen H. Ny Oppgavefordeling mellom personellgrupper i helse- og omsorgssektoren: veien å gå for å sikre framtidas velferdstjenester? [New division of labour between staff groups in the health and care sector: the path to take for safeguarding future welfare services?]. Rapport Uni Research Rokkansenteret 2. Oslo: Uni Research Rokkansenteret; 2014. Norwegian.

17. Universities Norway (UIR) [webpage on the Internet]. Sluttrapport fra sosialfaglig kompetanse og BSV-utdanningene. Sosialfagprosjektet. [Final report from social care competence and educational programmes for child care workers, social workers and social educators. Social studies project]; 2015:20. Available from: https://www.uhr.no/_f/p1/ i173466b6-cba4-4b8d-a8dc-0dbe503de56c/2015-bsv_prosjektets_sluttrapport_komplett_250915.pdf. Accessed January 15, 2019.

18. Axelsson SB, Axelsson R. From territoriality to altruism in interprofessional collaboration and leadership. J Interprof Care. 2009;23(4):320-330.

19. Reeves S, Macmillan K, van Soeren M. Leadership of interprofessional health and social care teams: a socio-historical analysis. J Nurs Manag. 2010;18(3):258-264.

20. San Martín-Rodríguez L, Beaulieu MD, D’Amour D, Ferrada-Videla M. The determinants of successful collaboration: a review of theoretical and empirical studies. J Interprof Care. 2005;19(Suppl 1):132-147.

21. West MA, Borrill CS, Dawson JF, Brodbeck F, Shapiro DA, Haward B. Leadership clarity and team innovation in health care. Leadersh $Q$. 2003;14(4-5):393-410.

22. Abbott A. The System of Professions: An Essay on the Division of Expert Labor. Chicago: University of Chicago Press; 1988.

23. Kooiman J. Governing as Governance. London: SAGE Publication; 2003.

24. Silverman D. Interpreting Qualitative Data: A Guide to the Principles of Qualitative Research. 4th ed. London: SAGE Publication; 2011.

25. Kvale S, Brinkmann S, Anderssen TM, Rygge J. Det kvalitative forskningsintervju [The Qualitative Research Interview]. 3rd ed. Oslo: Gyldendal Akademisk; 2015. Norwegian.

26. Vaismoradi M, Turunen H, Bondas T. Content analysis and thematic analysis: implications for conducting a qualitative descriptive study. Nurs Health Sci. 2013;15(3):398-405. 
27. Thagaard T. Systematikk og innlevelse: en innføring $i$ kvalitativ metode [Systematics and Insight: An Introduction to Qualitative Methods]. 4th ed. Bergen: Fagbokforlaget; 2018. Norwegian.

28. Ministry of Health and Care Services [webpage on the Internet]. Forskrift om ledelse og kvalitetsforbedring i helse- og omsorgstjenesten [Regulations concerning management and quality improvement in the health and care sector]; 2016. Available from: https://lovdata.no/dokument/LTI/forskrift/2016-10-28-1250. Accessed January 15, 2019.
29. Ministry of Health and Care Services [webpage on the Internet]. Fremtidens primærhelsetjeneste - nærhet og helhet (The primary health and care services of tomorrow - localised and integrated). In. Meld. St. 26 (2014-2015). Oslo: Departementenes servicesenter; 2015:168. Available from: https://www.regjeringen. no/contentassets/d30685b2829b41bf99edf3e3a7e 95d97/no/pdfs/ stm201420150026000dddpdfs.pdf. Accessed January 15, 2019.
Journal of Multidisciplinary Healthcare

\section{Publish your work in this journal}

The Journal of Multidisciplinary Healthcare is an international, peerreviewed open-access journal that aims to represent and publish research in healthcare areas delivered by practitioners of different disciplines. This includes studies and reviews conducted by multidisciplinary teams as well as research which evaluates the results or conduct of such teams or health

\section{Dovepress}

care processes in general. The journal covers a very wide range of areas and welcomes submissions from practitioners at all levels, from all over the world. The manuscript management system is completely online and includes a very quick and fair peer-review system. Visit http://www.dovepress.com/ testimonials.php to read real quotes from published authors.

Submit your manuscript here: https://www.dovepress.com/journal-of-multidisciplinary-healthcare-journal 